\title{
Off-label use of intravitreal triamcinolone acetonide for diabetic macular edema in a pregnant patient
}

This article was published in the following Dove Press journal:

Clinical Ophthalmology

6 April 201I

Number of times this article has been viewed

\author{
Ahad Fazelat \\ Kameran Lashkari \\ Schepens Eye Research Institute, \\ Harvard Medical School, \\ Boston, MA, USA
}

Correspondence: Ahad Fazelat

243 Charles Street, Boston,

MA 02। 14-3096, USA

$\mathrm{Tel}+\mathrm{I} 6175734199$

Fax + I 6178646437

Email ahad_fazelat@meei.harvard.edu

\begin{abstract}
We present a case of diabetic macular edema in a pregnant patient treated with a single intravitreal injection of triamcinolone acetonomide. Initial presentation and serial examinations after treatment included visual acuity, slit-lamp examination, indirect ophthalmoscopy, and optical coherence tomography. Resolution of visual acuity and macular edema were present six weeks after injection and persisted throughout the duration of the pregnancy without further intervention. No adverse outcomes for either mother or fetus were noted. To our knowledge, this is the first report of intravitreal triamcinolone administration in this patient population to be published in the medical literature.
\end{abstract}

Keywords: triamcinolone, macular edema, diabetes, pregnancy

\section{Case report}

A pregnant 23-year-old female with a six-year history of Type 1 diabetes presented with a complaint of increased "blur" in both eyes for the previous two months. Her most recent hemoglobin $\mathrm{A}_{1 \mathrm{c}}$ was measured at $6.4 \%$. She was six months' pregnant at initial presentation. On examination her best corrected visual acuity was 20/40 OU. Slit-lamp examination was entirely unremarkable in both eyes. Dilated funduscopic examination was significant for flame-shaped, dot, and blot hemorrhages in the posterior segment, with associated macular edema and exudates bilaterally (Figures 1A and 1B). No retinal neovascularization was noted. Optical coherence tomography (OCT) revealed a foveal thickness of $578 \pm 5$ microns and $667 \pm 8$ microns in the right and left eye, respectively (Figures 2A and 2B). All OCT scans were performed with the Stratus ${ }^{\circledR}$ optical coherence tomograph (Zeiss-Humphrey Inc, Dublin, CA).

Examination findings were consistent with bilateral, nonproliferative diabetic retinopathy and clinically significant macular edema. After careful deliberation with the patient and her obstetrician, a decision was made to treat the bilateral macular edema with intravitreal triamcinolone acetonide injection. The patient received $0.05 \mathrm{~mL}$ of triamcinolone acetonide $40 \mathrm{mg} / \mathrm{mL}$ in the left eye initially and in the right eye one week later.

The patient returned for re-examination six weeks after treatment. Best-corrected visual acuity was 20/20 and 20/25 in the right and left eye, respectively. Funduscopic examination revealed marked reduction in macular edema bilaterally. Repeat OCT revealed a foveal thickness of $159 \pm 5$ microns and $202 \pm 6$ microns in the right and left eye, respectively (Figures $3 \mathrm{~A}$ and $3 \mathrm{~B}$ ).

Four months after treatment, the patient's visual acuity remained stable bilaterally. Slit-lamp examination and Goldman applanation tonometry did not reveal any 

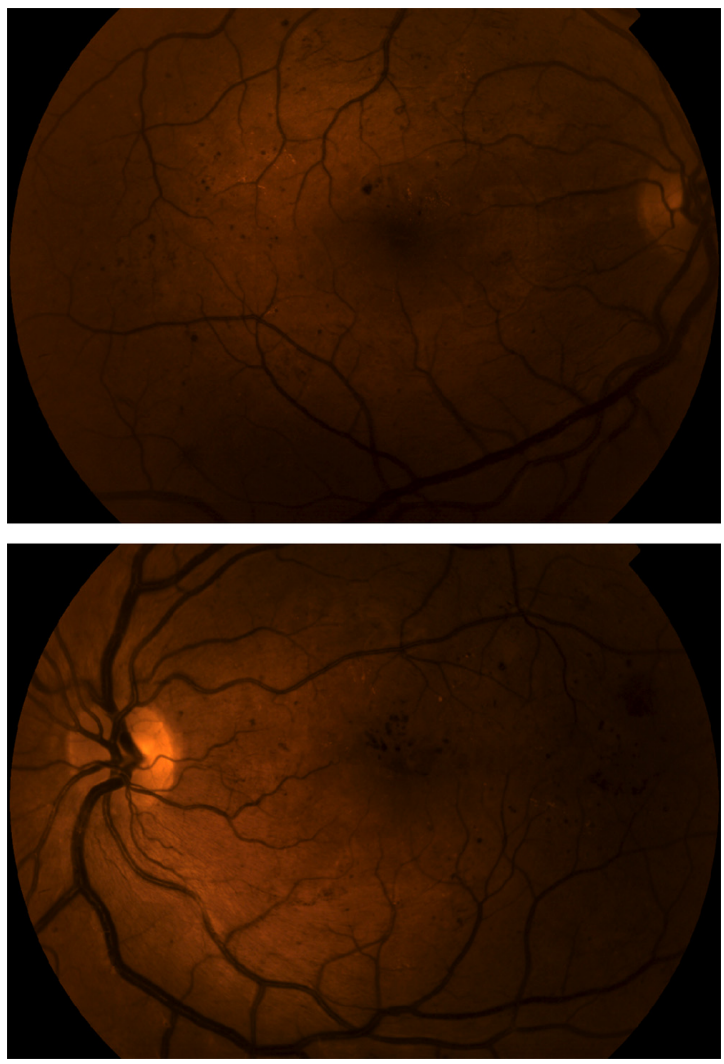

Figure I A) Color fundus photograph of the right eye. B) Color fundus photograph of the left eye.
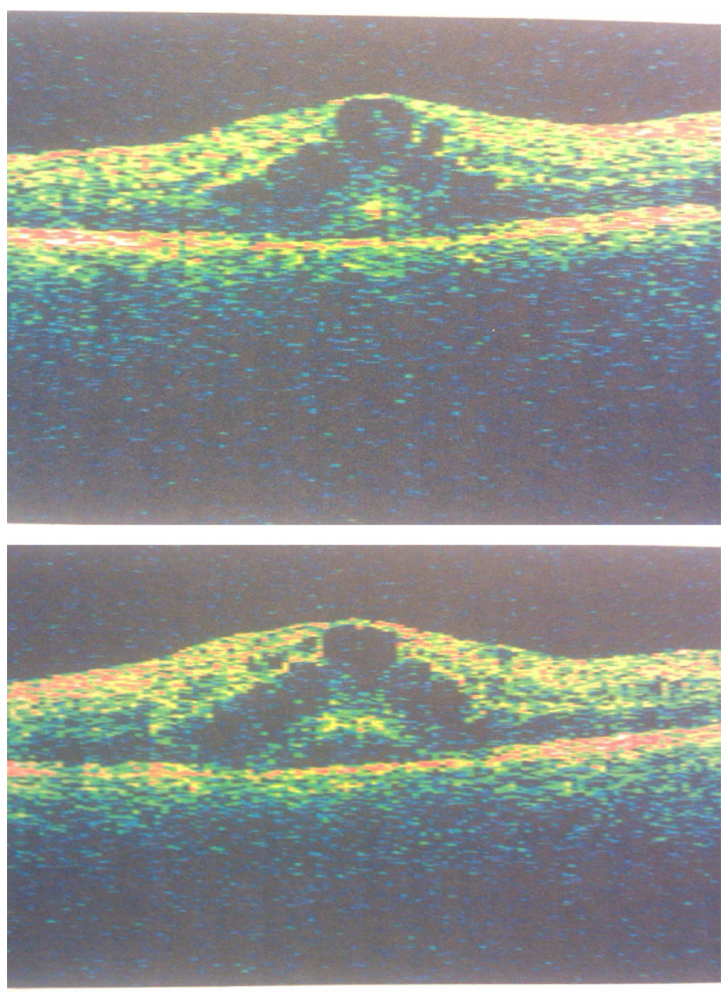

Figure 2 A) Optical coherence tomograph of macula at initial presentation, right eye. B) Optical coherence tomograph of macula at initial presentation, left eye.
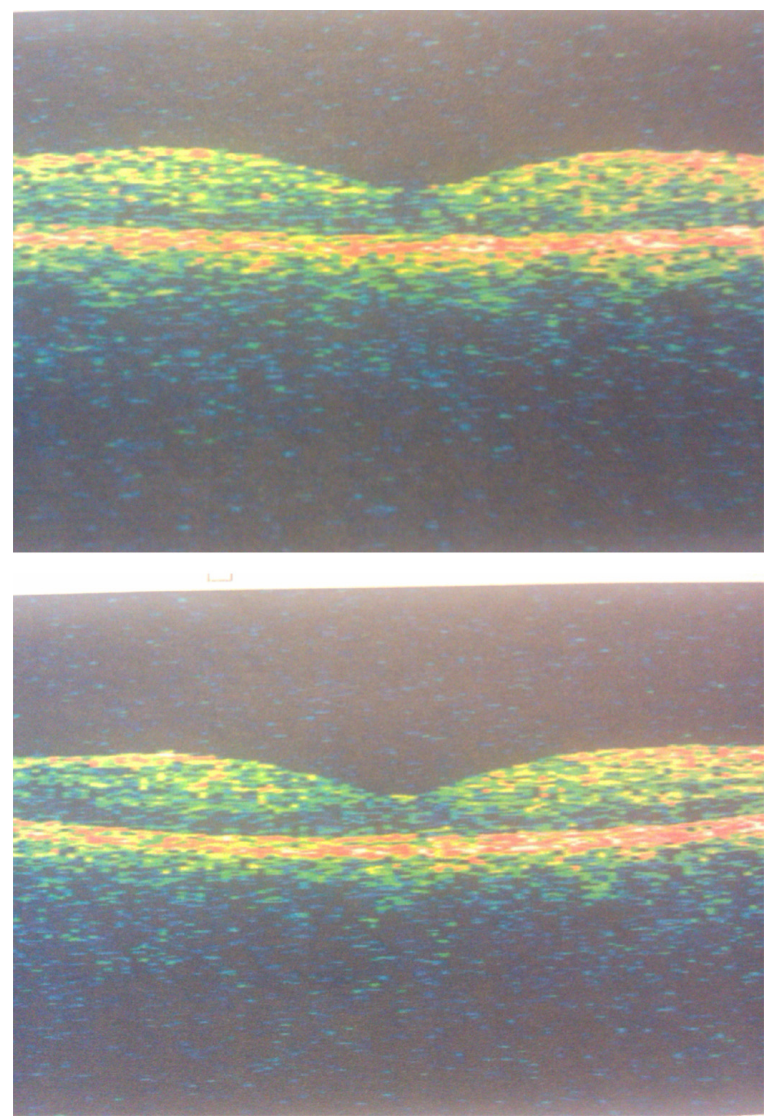

Figure 3 A) Optical coherence tomograph of macula at six weeks following injection, right eye. B) Optical coherence tomograph of macula at six weeks following injection, left eye.

intraocular hypertension or significant lenticular changes at this visit or at any point after triamcinolone injection. Funduscopic examination revealed only mild retinal thickening in the left eye. The patient delivered a full-term, healthy baby boy weeks prior to this examination. The patient reported no complications in pregnancy or parturition.

\section{Discussion}

Progression of diabetic retinopathy during pregnancy has been described previously by several authors. ${ }^{1,2}$ Visual impairment in these cases can result from both proliferative (eg, vitreous hemorrhage, retinal detachment) and nonproliferative etiologies (eg, retinal hemorrhage, papillopathy, macular edema)..$^{1}$ Although macular edema may regress in some cases after delivery, in other cases edema can persist and can be associated with severe and persistent visual dysfunction. ${ }^{1}$

Data from large, randomized clinical trials have established the benefits of argon laser photocoagulation for clinically significant macular edema. ${ }^{3}$ Focal laser photocoagulation of actively leaking blood vessels or grid laser for areas of 
diffuse permeability can decrease clinically significant edema. However, laser photocoagulation in close proximity to the fovea increases the risk of inducing iatrogenic central scotoma as a result of thermal injury to the tissues, or subsequent glial proliferation.

There are many reports of off-label use of intravitreal triamcinolone in cases of persistent and refractory diabetic macular edema. ${ }^{4}$ Improved visual acuity and decreased foveal thickness have been documented by serial OCT after a single injection. However, these effects do not appear to persist beyond 3-4 months without repeated administration. ${ }^{5}$ A Medline search using keywords "pregnancy", "pregnant", "clinically significant macular edema", "gestational diabetes", and "triamcinolone acetonide" revealed no case reports or case series documenting the treatment of clinically significant macular edema with intravitreal corticosteroids in a pregnant patient.

Side effects of systemic corticosteroid administration are well known. Major ophthalmic complications of intravitreal corticosteroid injection include, but are not limited to, cataract formation and increased intraocular pressure. Although corticosteroid equivalents can be measured in the aqueous three months after a single intravitreal injection, it is not known how much corticosteroid is released into the systemic circulation after a single intravitreal injection. ${ }^{6}$ Thus, it is hard to estimate the systemic effects of intravitreal corticosteroid therapy.

To date, there are no reports of teratogenic outcomes with systemic corticosteroid use in pregnant human females. However, teratogenic effects have been observed in many species receiving equivalent systemic human doses. ${ }^{7}$ Many authors have noted maxillofacial deformity and, in particular, cleft palate in mice which have received corticosteroids early in gestation.

Our patient presented with bilateral clinically significant diabetic macular edema and diminishing vision. The area of greatest thickening was within the fovea of both the right and left eyes, with little edema observed in the extrafoveal area. Laser photocoagulation to this area carried a significant risk of inducing a permanent central scotoma. We consulted the patient's obstetrician about the possibility of initiating intravitreal corticosteroid therapy. Given the patient's late stage of pregnancy, we felt that intravitreal steroid posed little risk to either mother or fetus. We were able to achieve resolution of macular edema and improved visual acuity with a single intravitreal dose to each eye.

In conclusion, we propose that intravitreal triamcinolone injection may be a viable treatment modality for management of clinically significant macular edema in pregnant patients. The safety profile with administration of this medication is enhanced if the steroid is administered after the first trimester. We suggest a multidisciplinary approach and consultation with an obstetrician whenever using corticosteroid therapy in pregnant patients.

\section{Disclosure}

The authors report no conflicts of interest in this work.

\section{References}

1. Sinclair SH, Nessler C, Foxman B, Nicholas CW, Gabbe S. Macular edema and pregnancy in insulin-dependent diabetes. Am J Ophthalmol. 1984;97:154-167

2. Moloney JB, Drury MI. The effect of pregnancy on the natural course of diabetic retinopathy. Am J Ophthalmol. 1982;93:745-756.

3. Early Treatment Diabetic Retinopathy Study Research Group. Treatment techniques and clinical guidelines for photocoagulation of diabetic macular edema. Early Treatment Diabetic Retinopathy Study Report Number 2. Ophthalmology. 1987;94:761-774.

4. Chieh JJ, Roth D, Liu M, et al. Intravitreal triamcinolone acetonide for diabetic macular edema. Retina. 2005;25:828-834.

5. Diabetic Retinopathy Clinical Research Network. A randomized trial comparing intravitreal triamcinolone acetonide and focal/grid photocoagulation for diabetic macular edema. Ophthalmology. 2008;115 1447-1459.

6. Furukawa S, Usada K, Abe M, Ogawa I. Histopathological findings of cleft palate in rat embryos induced by triamcinolone acetonide. $J$ Vet Med Sci. 2004;66:397-402.

7. Kenalog-40 injection [Package insert]. Princeton, NJ: Bristol-Myers Squibb Company; 2007.
Clinical Ophthalmology

\section{Publish your work in this journal}

Clinical Ophthalmology is an international, peer-reviewed journal covering all subspecialties within ophthalmology. Key topics include: Optometry; Visual science; Pharmacology and drug therapy in eye diseases; Basic Sciences; Primary and Secondary eye care; Patient Safety and Quality of Care Improvements. This journal is indexed on

\section{Dovepress}

PubMed Central and CAS, and is the official journal of The Society of Clinical Ophthalmology (SCO). The manuscript management system is completely online and includes a very quick and fair peer-review system, which is all easy to use. Visit http://www.dovepress.com/ testimonials.php to read real quotes from published authors. 